DOI: https://doi.org/10.47405/mjssh.v5i10.523

\begin{tabular}{|c|c|}
\hline 4.581 & Malaysian Journal of Social Sciences and Humanities (MJSSH) \\
\hline $\begin{array}{l}\text { Malaysian Journal of } \\
\text { socal s ciences and }\end{array}$ & Volume 5, Issue 10, October 2020 \\
\hline (MJ-SSH) & e-ISSN : 2504-8562 \\
\hline & $\begin{array}{l}\text { Journal home page: } \\
\text { www.msocialsciences.com }\end{array}$ \\
\hline
\end{tabular}

\title{
Penggunaan Sumber Dokumen Teks dalam Subjek Sejarah: Satu Sorotan Kajian
}

\author{
M. Kaviza ${ }^{1}$ \\ 1Pusat Pengajian Pendidikan dan Bahasa Moden, Universiti Utara Malaysia (UUM) \\ Correspondence: M. Kaviza (kavizakaviza@yahoo.com)
}

\begin{abstract}
Abstrak
Kajian ini meneroka tentang penggunaan sumber dokumen teks dan potensinya dalam proses pengajaran dan pembelajaran subjek sejarah. Kajian ini telah mengupas kajian-kajian lepas untuk mendalami kepentingan sumber dokumen teks bagi mewujudkan suasana pembelajaran yang menarik agar dapat merangsang murid berfikir.
\end{abstract}

Kata kunci: sumber dokumen teks, subjek sejarah, kajian literatur

\section{Text Document Sources Use in History Subject: A Literature Review}

\begin{abstract}
This study explore the text document sources use dan their potential in the process of teaching and learning history subject. This study explore the previous studies to understand in deep about the importance of text document sources to create an attractive learning environment to stimulate students' thinking.
\end{abstract}

Keywords: text document sources, history subject, literature review

\section{Pengenalan}

Sejarah ialah subjek teras dalam Kurikulum Standard Sekolah Menengah (KSSM) yang wajib dipelajari oleh semua murid secara berterusan dari Tingkatan Satu hingga Tingkatan Lima. Kurikulum Sejarah sekolah menengah dilaksanakan secara bersepadu yang merangkumi aspek kandungan pengetahuan, kemahiran pemikiran sejarah elemen kewarganegaraan dan nilai sivik. Kandungan sejarah adalah berbentuk kronologi yang membincangkan perihal kehidupan masyarakat dan negara daripada aspek politik, ekonomi dan sosial yang disusun secara kronologi supaya murid dapat memahami proses perkembangan masyarakat dan negara (Pusat Perkembangan Kurikulum [PPK], 2018). Sehubungan dengan itu, pembelajaran subjek sejarah telah membolehkan murid-murid dapat membuat perbandingan peradaban yang dicapai dan mempersiapkan diri mereka untuk bersaing di peringkat global. Justeru, bagi mencapai aspirasi pendidikan negara tersebut, maka pedagogi dan bahan pembelajaran yang mampu merangsang minat dan mencabar intelek murid diperlukan dalam kurikulum subjek sejarah. Penggunaan sumber dokumen teks merupakan antara bahan sumber sejarah 
yang berpotensi untuk mengupayakan dan menzahirkan aplikasi pengetahuan, kemahiran dan nilai dalam proses pengajaran dan pembelajaran subjek sejarah.

\section{Takrifan Sumber Dokumen Teks}

Sumber dokumen teks ditakrifkan sebagai bahan berbentuk teks yang menyediakan maklumat tentang sesuatu perkara dan kejadian yang telah berlaku pada masa lepas secara bertulis dan bercetak (Barton, 2005; Callison, 2013), manakala Pivkina, Ranjan dan Loddr (2009) dan Sandwell (2008) pula telah mendefinisikan sumber dokumen teks sebagai rekod bertulis yang direka bentuk berdasarkan proses pengkajian pada masa lepas yang digunakan untuk membuat pentafsiran terhadap sesuatu peristiwa sejarah pada masa ini. Takrifan ini adalah sealiran dengan takrifan yang diutarakan oleh Kobrin (1996) dan Breakstone dan Smith (2013) yang telah mendefinisikan sumber dokumen teks sebagai bahanbahan berbentuk teks yang digunakan sebagai bahan bukti sejarah bagi membuka ruang dalam proses pengkajian sejarah dengan membuat interpretasi sama ada secara individu mahupun secara kolektif terhadap sesuatu peristiwa sejarah yang telah berlaku. Justeru, dapat dirumuskan bahawa sumber dokumen teks merupakan bahan berbentuk teks atau bertulis yang digunakan untuk memerihalkan dan mentafsir sesuatu maklumat sejarah.

\section{Jenis-jenis Sumber Dokumen Teks}

Sumber dokumen teks terdiri daripada sumber primer iaitu rekod-rekod sebenar yang bersifat asli yang menerangkan sesuatu peristiwa yang telah berlaku pada masa lampau seperti manuskrip, rekod rasmi kerajaan, surat dan sebagainya, manakala sumber sekunder merupakan pembentukan teks daripada interpretasi dan pengalaman orang lain yang menerangkan sesuatu peristiwa lepas seperti buku sejarah dan ensiklopedia (Fitzgerald, 2009; Maffia, 2019; Newmann, 2001; Sandwell, 2008). Sumber dokumen teks juga telah diklasifikasikan sebagai sumber yang diterbitkan iaitu bahan yang kerap digunakan oleh ahli sejarah dan masyarakat umum seperti buku sejarah, majalah, surat khabar, ensiklopedia dan sebagainya yang diletakkan untuk pinjaman dan dimuat turun oleh pengguna sama ada dalam bentuk analog mahupun dalam bentuk digital, manakala sumber yang tidak diterbitkan merupakan bahan yang jarang-jarang digunakan oleh ahli sejarah dan masyarakat umum seperti surat peribadi, diari, jurnal, dokumen lama, manuskrip lama, rekod kerajaan dan sebagainya yang disimpan rapi dalam koleksi khas di Arkib (Lamb, 2014; Malkmus, 2008; Brown \& Dotson, 2007; Library of Congress, 2018; Singleton \& Giese, 1999).Terdapat ribuan koleksi sumber dokumen teks bertulis yang berpotensi digunakan dalam proses pengajaran pembelajaran mata pelajaran sejarah seperti rekod keluarga, rekod banci, wasiat, rekod tanah perkuburan, rekod kelahiran dan kematian, surat khabar, rekod mahkamah, buku sejarah, rekod tentera, rekod perniagaan dan industri, dan rekod kerajaan tempatan (Sandwell, 2008; Hendry, 2007; Lamb, 2013; Huistra \& Mellink, 2016). Justeru, sumber dokumen teks berpotensi digunakan bagi membentuk proses pembelajaran yang bermakna seperti yang disarankan dalam struktur disiplin ilmu sejarah yang menggalakkan penggunaan sumber sejarah sebagai bahan bukti konkrit untuk mendapatkan maklumat, pengetahuan dan kemahiran tertentu bagi menajawab persoalan sejarah yang diutarakan (Alves, 2014; Brown, 2007; Zastrow, 2017).

\section{Teknologi Pendigitalan Sumber Dokumen Teks}

Perkembangan teknologi pendigitalan dalam bidang pendidikan Sejarah telah menyediakan bahanbahan pengkajian sejarah secara percuma. Teknologi pendigitalan sumber dokumen teks ini dapat membentuk proses pembelajaran Sejarah yang lebih menarik dan melahirkan murid yang berliterasi, celik ilmu sejarah dan berpemikiran kritis (Nygren, 2014; Lee, 2002; Putnam, 2016; Fry \& Ensminger, 2008; Tally \& Goldenberg, 2005). Hal ini demikian kerana guru dan murid boleh mendapatkan koleksi sumber dokumen teks secara analog dan digital bagi meningkatkan pemahaman sejarah dan minat belajar sejarah (Shakila Yacob, 2007; Oliver \& Purichia, 2018; Shakila Yacob, Ahmad Kamal Arifin Mohd Rus \& Rosilawati Zainol, 2016). Selain itu, perkembangan teknologi pendigitalan membolehkan proses pembelajaran Sejarah yang berkesan dapat dibentuk melalui penggunaan sumber digital untuk 
meningkatkan kemahiran pemikiran sejarah selaras dengan perkembangan strategi pembelajaran abad ke-21 (Abdul Razaq Ahmad, 2014; Renuka Ramakrishnan \& Siti Hawa Abdullah, 2012). Justeru, pembangunan arkib digital atau portal sejarah yang menyediakan ribuan pautan dan koleksi sumber dokumen teks dapat memudahkan guru dan murid untuk memuat turun bahan sejarah yang diperlukan mengikut topik atau tema sejarah yang tertentu (Grant \& Gradwell, 2005; Chassanoff, 2013; Friedman, 2006; Hicks, Doolittle \& Lee, 2004; Hover, Hicks \& Dack, 2016).

\section{Kepentingan Penggunaan Sumber Dokumen Teks}

Kepentingan penggunaan sumber dokumen teks ialah:

1. Murid-murid berupaya untuk membuat perbandingan antara sumber primer dan sumber sekunder. Perkara ini disebabkan oleh kesahihan dan kebenaran terhadap sesuatu peristiwa sejarah adalah lebih tinggi dalam sumber primer berbanding dengan sumber sekunder yang berkemungkinan diragui kesahihan dan kebenaran fakta tersebut.

2. Murid-murid berupaya untuk berfikir secara rasional dengan menentukan kesan positif dan kesan negatif di sebalik berlakunya sesuatu peristiwa sejarah. Hal ini demikian kerana unsur objektiviti sejarah yang diperolehi dalam sumber sejarah adalah lebih tinggi.

3. Murid-murid berupaya untuk menggambarkan semula sesuatu rentetan atau situasi peristiwa sejarah yang telah berlaku dengan sokongan bahan bukti yang konkrit dan relevan. Hal ini demikian kerana murid didapati sukar untuk menentukan realiti atau gambaran sebenar terhadap sesuatu peristiwa sejarah masa lampau disebabkan mereka tidak wujud semasa peristiwa sejarah tersebut.

4. Murid-murid berupaya untuk meningkatkan minat belajar sejarah apabila peluang pembelajaran Sejarah yang dapat menggalakkan mereka berperanan sebagai seorang ahli sejarah yang berpengalaman dengan membuat analisis sumber sejarah dapat dibentuk. Hal ini demikian kerana kaedah pengajaran yang menumpukan kepada penyalinan nota dan penghafalan fakta menyebabkan murid-murid berasa cepat bosan dan menganggap mata pelajaran Sejarah sebagai mata pelajaran yang tidak mencabar proses pemikiran mereka.

5. Murid-murid berupaya untuk meningkatkan kebolehan dan daya intelektual secara kritis dan analitis melalui proses pengumpulan, penilaian dan penganalisisan sumber sejarah bagi membuat sesuatu pentafsiran sejarah yang mendalam.

(Hazri Jamil, 2003; Barton, 2018; Humber, 2008;

Padilha, Bellaguardo, Nelson, Maia \& Costa, 2017; Barnett, 2014)

\section{Pengingtegrasian Sumber Dokumen Teks Dalam Pengajaran dan Pembelajaran}

Pengingtegrasian sumber dokumen teks ialah:

1. Dengan memperkenal sesuatu idea sejarah secara kontekstualisasi yang membolehkan murid dapat menganalisis bukti sejarah secara kritis.

2. Dengan menyediakan senarai rujukan kepada murid untuk membuat pembacaan secara mendalam agar penguasaan pengetahuan kandungan, kemahiran penyelidikan dan pemikiran kritis dapat dijana.

3. Dengan menggalakkan murid membuat perkaitan antara suatu tema, isu atau peristiwa sejarah dengan suatu tema, isu atau peristiwa sejarah yang lain bagi menjana suatu idea sejarah yang bersifat lebih kompleks

4. Dengan menjana nilai tambah dalam pembelajaran Sejarah melalui pemerolehan kandungan pengetahuan sejarah selain buku teks dan menggalakkan penglibatan aktif murid dengan membuat pembentangan atau perbincangan sesuatu peristiwa sejarah daripada pelbagai perspektif.

5. Dengan menjana pengetahuan sedia ada dan membina makna kepada pengetahuan tersebut dan membentuk konteks pengkajian yang tersendiri berdasarkan penggunaan sumber dokumen yang mudah.

6. Dengan menjana pemahaman dan pemikiran kritis melalui persoalan atau isu yang dikemukakan yang memerlukan murid-murid mencari maklumat daripada pelbagai 
perspektif bagi menjawab persoalan tersebut berdasarkan pengadilan dan kriteria yang ditetapkan.

(Sandwell, 2008; Woyshner, 2010; Neumann, 2015)

\section{Potensi Penggunaan Sumber Dokumen Teks dalam Pengajaran dan Pembelajaran}

Penggunaan sumber dokumen teks adalah berupaya untuk menyediakan peluang pembelajaran yang membolehkan murid-murid dapat membezakan antara sumber primer dan sumber sekunder serta meningkatkan pemahaman terhadap kebolehpercayaan dan kredibiliti sumber dokumen teks tersebut (Harris, Halvorse \& Aponte-Martinez, 2015; Stromso, Braten \& Britt, 2011; McGrew, Breakstone, Ortega, Smith \& Wineburg, 2018; Macedo-Rouet, Braasch, Britt \& Rouet, 2013; Leporati, Bach \& Hong, 2019).Selain itu, penggunaan sumber dokumen teks secara berterusan adalah terbukti dapat meningkatkan pemerolehan maklumat sejarah yang banyak dan dapat menjana proses pemikiran sejarah secara analitikal (Allen, 2011; Clark, 2014; Nersater, 2019). Hal ini demikian kerana analisis sumber dokumen teks membolehkan murid-murid dapat mentafsir, meneroka, menganalisis dan mensintesis pelbagai maklumat sejarah untuk membuat suatu interpretasi sejarah yang bersifat naratif, disamping dapat meningkatkan kemahiran pemikiran sejarahdan berperanan sebagai ahli sejarah yang berpengalaman (Nieuwenhuyse, Roose, Wils, Depaepe, Verschaffel, 2017; Marino, 2012; Gaffield, 2000; Fitzgerald, 2019; Boerman-Cornell, 2015; Bickford, 2010).

\section{Implikasi Penggunaan Sumber Dokumen Teks dalam Mata Pelajaran Sejarah}

Implikasi penggunaan sumber dokumen teks dalam mata pelajaran sejarah ialah:

1. Kaedah pengajaran konvensional perlu diubah daripada penghafalan fakta sejarah kepada proses pengkajian sejarah, penguasaan kandungan sejarah dan peningkatan kemahiran berfikir aras tinggi dan penglibatan aktif melalui penggunaan sumber dokumen teks.

2. Guru-guru perlu dilatih untuk mengingtegrasikan sumber dokumen teks melalui pelaksanaan latihan dan bengkel yang berlandaskan kepada struktur disiplin ilmu sejarah, pemikiran sainstifik dan proses penyiasatan dunia sebenar.

3. Keperluan pendigitalan koleksi sumber dokumen teks oleh pihak arkib dan muzium bagi memudahkan guru-guru sejarah untuk memuat turun, mengakses dan memilih bahan tersebut dari sekolah masing-masing walaupun fokus perlu diberikan kepada pemilihan sumber yang relevan.

4. Pihak Institut Pendidikan Guru dan Institut Pengajian Tinggi Awam perlu merancang kursus pedagogi yang berteraskan penggunaan sumber dokumen teks sebagai salah satu kaedah pengajaran sejarah untuk dipratikkan dalam kalangan guru-guru pelatih.

5. Pihak PPK perlu memberikan perhatian kepada pembinaan modul pengajaran dan pembelajaran berasaskan penggunaan sumber dokumen teks mengikut tema atau topik sejarah sebagai panduan dalam membentuk proses pembelajaran sejarah yang menarik dan interaktif.

(Dutt-Doner, Cook-Cottone \& Allen, 2007; Dutt-Doner \& Allen, 2015; Moser, 2013; Chick, 2006; Swams, Hofer \& Gallicchio, 2006; Gruber, 2017; Langan, 2015)

\section{Kesimpulan}

Kesimpulannya, sumber dokumen teks berpotensi menyediakan peluang pembelajaran yang membolehkan murid-murid dapat memproses maklumat sejarah bagi meningkatkan pengetahuan, kemahiran dan nilai dalam kalangan murid. Implikasi kajian ini diharapkan dapat menjadi sumber maklumat kepada para guru dan murid untuk meningkatkan mutu proses pengajaran dan pembelajaran mata pelajaran sejarah dengan menekankan strategi pembelajaran mendalam, pendekatan berpusatkan murid dan penglibatan aktif. 


\section{Rujukan}

Abdul Razaq Ahmad. (2014). Determination of teaching aids and methods to inculcate thinking skills in history subjects. TAWARIKH: International Journal for Historical Studies, 6(1), 1-12.

Allen, R.B. (2011, Ogos). Developing a knowledge-based to improve interaction with collections of historical newspapers. Kertas kerja yang dibentangkan di International Federation of Library Association (IFLA), San Juan, Puerto Rico.

Alves, D. (2014). Introduction: digital methods and tools for historical research. International Journal of Humanities and Arts Computing, 8(1), 1-12.

Ankeney, K., Frankel, M \& Whisner, R. (2004). A story well told: Primary sources and History Education. Social Studies Review-Summer, 1.

Barnett, A. (2014). A primary motivation: The importance of primary sources in teaching literacy. Kentucky Reading Journal, 32-41.

Barton, K.C. (2005). Primary sources in history: Breaking through the myths. Phi Delta Kappan, $86(10), 745-753$.

Barton, K.C. (2018). Historical sources in the classroom: Purpose and use. HSSE Online, 7(2), 1-11.

Bickford III, J.H. (2010). Complicating students' historical thinking through primary sources reinvention. Social Studies Research \& Practices, 5(2), 47-60.

Boerman-Cornell, W. (2015). Using historical graphic novels in high school history classes: Potential for contextualization, sourcing, and corroborating. The History Teacher, 48(2), 209-224.

Breakstone, J., \& Smith, M. (2013). Using library of congress primary sources for assessment. The TPS Journal, 1(3), 1-8.

Brown, C.A. (2007). Using digital primary sources: A success story in collaboration. Teacher Librarian, 35(2), 29-33.

Brown, C.A., \& Dotson, K. (2007). A case study using digital primary source documents. Tech Trends, 51(3), 30-37.

Callison, D. (2013). CCSS: Primary sources for secondary social studies. School Library Monthly, $30(2), 18-21$.

Chassanoff, A. (2013). Historians and the use of primary source materials in the digital age. The American Archivist, 76(2), 458-479.

Chick, K.A. (2006). Fostering student collaboration through the use of historical picture books. The Social Studies, 152-157.

Clark, J.S. (2014). Teaching historical agency: explicitly connecting past and present with graphic novels. Social Studies Research and Practice, 9(3), 66-80.

Dutt-Doner, K., Cook-Cottone, C., \& Allen, S. (2007). Improving classroom Instruction: Understanding the developmental nature of analyzing primary sources. Research in Middle Level Education, 30(6), 1-20.

Dutt-Doner, K.M., \& Allen, S. (2015). Increasing pre-service teachers' capacity to utilize and implement primary source instruction in the elementary Classroom. National Teacher Education Journal, 8(1), 13-24.

Fitzgerald, J.C. (2009). Textbooks and primary source analysis. Social Studies Research and Practice, $4(8), 37-43$.

Fitzgerald, J.C. (2019). Teaching the reasons why: An analysis of causation in history textbooks and historical primary sources documents. Universal Journal of Educational Research, 7(4), 10271036.

Friedman, A.M. (2006). World history teacher's use of digital primary sources: The effect of training. Theory \& Research in Social Education, 34(1), 124-141.

Fry, M.L., \& Ensminger, D.C. (2008). Integration of digital primary sources, 441- 448.

Gaffield, C. (2000). Primary sources, historical thinking, and the emerging redefinition of the B.A. as a research degree. Facsimile, 12-17.

Grant, S.G \& Gradwell, J.M. (2005). The sources are many: exploring history teachers' selection of classroom texts. Theory \& Research in Social Education, 33(2), 244-265.

Gruber, G. (2017). Teaching issues of contemporary history using historical sources and modern teaching methods. MATEC Web of Conferences, 121, 1-7. 
Harris, L.M., Halvorsen, A.L., \& Aponte-Martinez, G.J. (2015). "[My] family has gone through that': How high school students determine the trustworthiness of historical documents. The Journal of Social Studies Research, 40, 109-121.

Hazri Jamil. (2003). Teknik mengajar sejarah. Pahang: PTS Publications \& Distributors Sdn Bhd.

Hendry, J. (2007). Primary sources in K-12 education: Opportunities for archives. The American Archivist, 70(1), 114-129.

Hicks, D., Doolittle. P. \& Lee, J.K. (2004). Social studies teachers' uses of classroom-based and webbased historical primary sources. Theory and Research in Social Education, 32(2), 213-247.

Hover, S.V., Hicks, D., \& Dack, H. (2016). From source to evidence? Teachers' use of historical sources in their classrooms. The Social studies, 107(6), 209 -217.

Huistra, H., \& Mellink, B. (2016). Phrasing history: Selecting sources in digital repositories. Historical Methods, 49(4), 220-229.

Humber, M. (2008). The value of using primary source documents in the history classroom. Capstone Essay: Peabody College, 1-20.

Kobrin, D. (1996). Beyond the textbook: Teaching history using documents and primary sources. Portsmouth, New Hampshire: Heinemann.

Lamb, A. (2014). Primary source digital documents: CCSS \& complexity of text. School Library Monthly, 30(4), 5-8.

Lamb, A., \& Johnson, L. (2013). Social Studies in the spotlight: Digital collections, primary sources and the common core. Teacher Librarian, 41, 62-66.

Langan, E. (2015). Using multiple-perspective primary sources to enhance pre-service teachers' understandings. Teacher Education and Practice, 28(4), 617-626.

Lee, J.K. (2002). Digital history in the history/social studies classrooms. The History Teacher, 35(4), 5-8.

Leporati, B, R., Bach, P., \& Hong, L. (2019). Learning to evaluate sources: Comparing teaching modalities and students outcomes. Libraries and the Academy, 19(1), 233-252.

Library of Congress. (2018). Using primary sources: Digital collection. Retrieved from https://www.loc.gov/collections/

Macedo-Rouet, M., Braasch, J.L.G., Britt, M.A \& Rouet, J.F. (2013). Teaching fourth and fifth graders to evaluate information sources during text comprehension. Cognition and Instruction, 31(2), 204-226.

Maffia, A. (2019). Exploring the potential of primary historical sources in primary schools: A focus on teacher's actions. International Journal of Mathematical Education in Science and Technology, 50(3), 354-368.

Malkmus, D.J. (2008). Primary source research and the undergraduate: A transforming landscape. Journal of Archival Organizations, 6(1-2), 47-70.

Marino, M. (2012). Urban space as a primary source: Local history and historical thinking in New York City. Social Studies, 103(3), 107-116.

McGrew, S., Breakstone, J., Ortega, T., Smith, M., \& Wineburg, S. (2018). Can students evaluate online sources? Learning from assessment of civic online reasoning. Theory \& Research in Social Education, 1-29.

Moser, D. (2013). Effects of student engagement with the use of digital primary sources in a high school social studies classroom.

Nersater, A. (2019). Students understanding of historical sources - A composite ability. Journal of Humanities and Social Science Education, 1, 105-131.

Neumann, D. (2015). Secondary sources in history classrooms: Disciplinary frameworks and student learning. Social Education, 79(4), 204-210.

Newmann, M. (2001). Primary Sources in perspective. Journal Educations and Students with Library of Congress Resources, 1-10.

Nieuwenhuyse, K.V., Roose, H., Wils, K., Depaepe, F., Verschaffel, L. (2017). Reasoning with and /or about sources? The use of primary sources in Flemish secondary school history education. Journal of Historical consciousness, historical cultures and history education, 4(2), 48-70.

Nygren, T. (2014). Student writing history using traditional and digital archives. Human IT, 12(3), 78116. 
Oliver, K.M., \& Purichia, H.R. (2018). Analyzing historical primary sources open educational resources: A blended pedagogical approach. Contemporary Issues in Technology and Teacher Education, 18(2), 392-415.

Padilha, M.I., Bellaguardo, M.L.D.R., Nelson, S., Maia, A.R.C., \& Costa, R. (2017). The use of sources in historical research. Reflection, 1-10.

Pivkina, I., Ranjan, D., \& Loddr, J. (Mac, 2009). Historical Sources as a Teaching Tool. Kertas kerja yang dibentangkan di SIGCSE'09, Chattanooga, Tennessee, USA.

Pusat Perkembangan Kurikulum. (2018). Dokumen standard kurikulum dan pentaksiran mata pelajaran sejarah tingkatan empat dan lima. Putrajaya: Kementerian Pendidikan Malaysia.

Putnam, L. (2016). The transnational and the text-searchable: Digitized sources and the shadows the cast. The American Historical Review, 121(2), 377-402.

Renuka Ramakrishnan \& Siti Hawa Abdullah. (2012, Oktober). Penggunaan Sumber Digital Dalam Kalangan Guru Sejarah. Kertas kerja yang dibentangkan di Seminar Kebangsaan Majlis Dekan Pendidikan IPTA, The Zon Regency by the Sea, Johor Bharu, Malaysia.

Sandwell, R.M. (2008). Using primary documents in social studies and history. The Anthology of Social Studies: Issues and Strategies for Secondary Teacher, 2, 295-307.

Shakila Yacob, Ahmad Kamal Ariffin Mohd Rus, Rosilawati Zainol. (2016). Potensi di luar tempurung: Hala tuju digitalisasi sejarah di Malaysia. Geografilian Online: Malaysian Journal of Society and Space, 12(13), 61-73.

Shakila Yacob. (2007). Digitalising history: A guide to history resources on the internet. Kuala Lumpur: Penerbit University Malaya.

Singleton, L.R., \& Giese, J.R. (1999). Using online primary sources with students. The Social Studies, 90(4), 148-151.

Stromso, H.I., Braten, I., \& Britt, M. A. (2011). Do students' beliefs about knowledge and knowing predict their judgement of text trustworthiness? Educational Psychology, 31, 177-206.

Swans, K.O., Hofer, M., \& Gallicchio, L. (2006). Historical scene investigating (HIS): Engaging students in case based investigations using web based historical documents. Social Studies research and Practice, 1(2), 250-261.

Tally, B., \& Goldenberg, L.B. (2005). Fostering historical thinking with digitized primary sources. Journal of Research on Technology in Education, 38(1), 1-21

Woyshner, C. (2010). Inquiry teaching with primary source documents: An iterative approach. Social Studies Research and Practice, 5(3), 36-45.

Zastrow, J. (2017, September). The digital archivist: Archives and activism engaging students with primary sources. InfoToday, 23-27. 